\title{
Netspeak and a Breach of Formality: Informalization and Fossilization of Errors in Writing among ESL and EFL Learners
}

\author{
Azianura Hani Shaari \\ School of Language Studies and Linguistics \\ Faculty of Social Sciences and Humanities \\ Universiti Kebangsaan Malaysia
}

\author{
Khaleel Bader Bataineh \\ English Language Department \\ Irbid National University, Jordan
}

\begin{abstract}
Netspeak refers to the language used in any online communication environment such as chat rooms, Facebook, or Twitter. By drawing on John Dewey's concept of habit formation, Baron believes that after years of constant use of Netspeak, language learners will naturally employ the features of this language into their formal writing practice [1]. This would happen when language violations such as spelling mistakes and the misuse of punctuations or capitalization have become acceptable and fossilized in learners' formal writing activities. This study will present findings of a research, primarily aimed at investigating the fossilization of errors in writing among ESL (Malaysians) and EFL (Jordanians) learners due to the aforementioned phenomenon.

Two research methods were employed: a questionnaire that was designed based on Selinker's theory of interlanguage and the factors contributing to the use of lexical features of Netspeak, and semistructured interviews. Questionnaires were administered to 300 participants; 150 Asian students from one public university in Malaysia (representing the ESL learners) and 150 Middle East students from the Irbid National University, Jordan (representing the EFL learners). This study managed to provide some valuable insights on the issues, by demonstrating some new perceptions and ideologies pertaining to the ignorance of language consistency in formal writing practice, resulting from a constant use of Netspeak in the online communication environment.
\end{abstract}

\section{Introduction}

The emergence of Netspeak has brought about studies from different areas of language. Early issues were raised concerning the lexical and syntactic features of Netspeak [5][1][2][22][10][14]; as well as its status; whether it should be categorized as a written or a spoken language [12][24][8]. Pallettieri suggests that the patterns of Netspeak used in the synchronous online communication (such as online chatting in chat rooms) are similar to those made in natural face-to-face conversations. Greenfield and Subrahmanyam also believe that the language used online (especially the one occurring in chat rooms) adopts features from both written and spoken language [8]. This is because online chatting, which occurs as a written discourse in the form of a dialogue carries many spoken features such as impromptu speech, incomplete sentences, less formal language, more colloquial, and contains shortened words and phrases with various grammatical errors. Greenfield and Subrahmanyam believe that Netspeak is "a register of written language with many of the stylistic features of spoken language" [8].

Scholars like Maynor and Crystal furthermore, classify the use of Netspeak in an asynchronous online communication (e-mail for instance), as a written speech or a unique form of language that stays in between written and spoken [5][12]. Ferrara, Bruner and Whittemore on the other hand, categorize Netspeak as "a hybrid language variety" or a "hybrid register". In terms of its hybrid characteristics of both spoken and written languages. Some other researchers define the status of Netspeak as a clear hybrid variety of English, a vibrant new medium of communication with its own unique style and a hybrid[24], a third medium [5], as well as a newly emerging, hybrid form with its own characteristics and uses. Finally, after thorough comparisons between Netspeak vs. both spoken and written languages, Crystal believes that Netspeak is neither spoken nor written, but a set of unique features that stands in between both spoken and written languages [5].

Researchers of Netspeak such as Crystal, Baron, and Shortis have different concerns and opinions towards the emergence of Netspeak, thus perceive the phenomenon from the following perspectives [5][1][22]. Firstly, Baron perceives Netspeak as a threat that jeopardizes the originality of the existing languages [2]. Through the massive use of abbreviations, acronyms, spelling modifications and abandonment of language rules in online interaction, Baron believes that the Internet users, especially youngsters, are getting more and more comfortable with this pattern of online lingo, pushing the Standard English language towards danger [2]. Crystal on the other hand, perceives the arrival of Netspeak as a positive phenomenon, as he describes 
the situation as "one remarkable diversity and creativity" with no signs of Netspeak replacing the existing varieties or bringing negative effects on the other languages [5]. Considering the language used online as a new form of communication, his bigger concern revolved around the issue of whether this language is significant enough to be categorized as a new variety. With its vague position on whether it should be generalized as a new variety [5], or as the outcome of the re-spelling phenomenon [22], or even as a threat to existing languages [2], it is believed that more in-depth studies are highly needed in considering its real status, functions and purposes, as well as the impacts that it might bring to its users.

It is also believed that the use of Netspeak (in English) will make the process of English language learning to become more difficult, especially among the non-native English speakers who are acquiring it as a second or a foreign language. This is due to the fact that the huge wavelength of Netspeak is not just a mere widespread trend, but moving towards establishing its status as a norm of today's communication, especially among the teenagers. A study conducted by Lee, for instance, reveals a significant shift from a standard to a non-standard language in communication among a group of Korean students. Students use Netspeak features in their school works and produced massive spelling errors as a result of non-standard ways of Internet language use, which made some negative impacts on their formal writing practices. For young learners who have not mastered their foreign or second language, being exposed to Netspeak may bring a huge impact on their entire process of language development [11]. This could be the result of the fossilization of errors committed through years of online communication practices, soon accepted as a normal habit in learners' writing practice [2].

As Netspeak grows along with time, there are still ongoing debates among researchers; on the effectiveness of Netspeak as a suitable and acceptable language in its own context. Scholars express different concerns from different perspectives, some are in favor of its existence, while some also show their approval, but are wary of the long-term effects it might bring on students' proficiency and level of competence, especially among both ESL and EFL learners.

Therefore, decisions and standpoint on the right attitudes towards online language need to be done in no time. Whether exemption and freedom should be given for Netspeak to spread and expand, with spelling errors and other sorts of grammatical mistakes being perceived as a sign of creativeness; or no tolerance should be given as it ingrain errors into becoming a strong system in one's language development. As there should be certain limits in one's expressions of creativity; at least without violating the rules of language, it being rule- governed, the fossilization of errors in online language should not be taken for granted.

\section{Massive Use of Netspeak Features Fossilizes Errors: A Shift from Formal to Informal Writing Conventions}

As much as Baron and many other scholars are concerned [2][13][8][5][4], the fossilization of errors as a result of a habitual online language usage could lead to certain impacts. Undoubtedly, this fossilization of errors, regardless of the nature; be it spelling modifications, abbreviations, acronyms, omissions of verbs and articles and many other forms of grammatical errors, may lead to certain influence on the learners' language development, especially the young ones [2]. This is in parallel with Krashen's concept of Natural Approach that indicates how language acquisition will be more effective when it is acquired subconsciously, through meaningful interactions, in natural communication environments. Suffice to say that an unhealthy or unfavorable natural 'learning' environment (like the online communication setting) might eventually produce a kind of outcome that is different from what learners are expected to achieve.

In a study involving a group of non-speaking English students in one higher learning institution, Berman reported how the use of SMS language has extended into the writing of formal letters among the participants. More surprisingly, Berman's findings indicate that most participants actually perceived that using online language in both formal and informal situations as something normal. Even though users are basically aware of the number of errors they committed through the use of online language, they believed that those errors are acceptable as they belong to the Standard English Language [4]. Berman's findings conform to Fairclough's idea of "informalization", who foresees that communication in the upcoming technological era would involve a blend of formal and informal patterns of languages, and this might include, "technical and non-technical vocabularies, markers of authority and familiarity, more typically written, and more typically spoken syntactic forms" [7]. The "casual attitude towards linguistic consistency" may lead to the fossilization of errors, which then resulting to the 'informalization' in both formal and informal writing conventions [2].

Montero-Fleta et. Al in their research also found a significant remark of 'informalization' in the use of online language among the students [13]. It is also found that online users are not really concern about language rules when communicating online [9].

Thurlow discusses about the worries and concern voiced out in many printed media around the globe, towards the unpopular use of traditional languages 
due to the domination of online language in the cyber world [25]. Weighing the issue from both negative and positive perspectives, Thurlow claims that,

It would also be untrue to suggest that there is nothing new or nothing distinctive about the stylistic practices of, for example, text messaging and instant messaging. What is less certain, however, is whether so-called Netspeak does indeed manifest such decisive or distinctive revolutionary break with conventional standards... Although it may not appear or feel like this for lay people, it seems far more likely from sociolinguistics and scholarly point of view that language and communication are changing and evolving as they always have [25].

Language, mainly English has undergone through stages of evolutions and modifications due to the development of technology and people's lifestyle [2][4]. The English spelling system, for instance, has gone several revolutionary processes, initiating from "the shift from a manuscript of medieval Europe to a print culture in early modern Europe [1][2], known as the 'age of print', back in the $17^{\text {th }}$ and $18^{\text {th }}$ century [22]; until it becomes established and remained stagnant for quite some time, at least until today. As the word 'unfriend' (derived from social websites like Facebook and Friendster) being listed in the New Oxford as 'Word of 2009', it is predicted that the current situation is not going to last that long. More changes and modifications will come in, as we expect tolerance in the use of modern verbs, words or phrases that were considered as errors not long ago. The English Language is becoming more lenient in tolerating with this invention of modern words.

As we couldn't agree more to Thurlow when he proclaims, "no lay speakers nowadays actually use the English of Shakespeare" [25], we also concern that the drastic changes shown by youngsters in their patterns of online writing will slowly become acceptable as their norm of communication in both formal and informal settings. As what Berman and others have found, the questions would be, are we ready to see "xs cmpnstn fnds wl b nvstd 4 srvvng fmly mmbrs" [4] in our students' formal writing products? Are we ready to accept this as a norm of today's communication in regard to this modernization and technology-oriented lifestyle? With the combination of different alphabets and numeric characters that seems to violate the basic rules of word formations Finegan, are we ready to see this form of writing as the next generation's writing style, and accept this nature as a form of creativity [5] in writing? As English is a "constantly changing language", what is determined as a
Standard English today, may be considered as an Old English tomorrow. Are we ready to accept the informal language in every formal writing convention that we have? Are we ready to see formal job application letters that sound more or less like a piece of conversation in a chat room?

\section{Interlanguage Theory}

One theory pertinent to this issue would be Selinker's Interlanguage Theory. This theory proposes some logical reasons and explanations why second language learners fail to reach a similar level of competence as native speakers. The theory of Interlanguage is also very much related to this study in providing relevant explanations and rationales behind the problems in ESL/EFL learning due to the constant use of certain lexical features and patterns of the English Language in the online communication environment (Netspeak), among the research participants.

According to the theory, the failure of one's mental or internal state of denativization would contribute to the high interference and influence of the learner's first language in their use of L2. This may also result in a learner's inability to distinguish between the separate linguistic systems of both L1 and L2. The theory of interlanguage also depicts an emergence of a linguistic system developed by a second language learner who has not achieved full competence and proficiency in the target language. This is the stage whereby some major features of L1 are still being preserved and employed in the use of L2, thus distorting a learner's ability to naturally understand and employ the rules of the target language due to a great level of confusion and language overgeneralization.

In other words, Interlanguage occurs when certain aspects of the target language do not match with a learner's existing language structure developed through his first language learning experience. O'Grady and Archibald outlined the scenario of Interlanguage in the following figure:

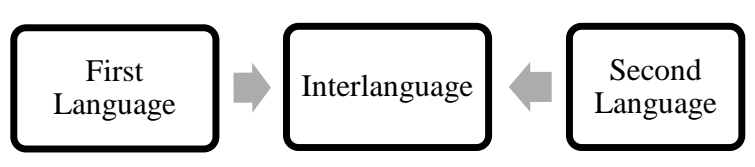

Figure 1: Interlanguage Grammar

During the process of second language acquisition, there is a high possibility for a learner to have to learn to produce some new features that could be foreign to their first language. In certain situations, interlanguage might be fossilized, or stop at any stage of language learning development [17]. 


\subsection{Other Factors Contributing to the Use of Lexical features of Netspeak in the Online Communication Environment}

There are some factors and reasons given by previous researchers related to the use of various features of Netspeak, which are also considered as variables of the survey question employed in this study. The factors are given as follows:

3.1.1. Whatever Generation. Firstly, Baron claims that the invasion of Netspeak has produced "the Whatever Generation" that adapt the language used online in both formal and informal writing practices. From modifications of spellings to the formation of abbreviations and acronyms, as well as the wrong usage of punctuations and apostrophes, the concept of language as being rule-governed has been excessively violated. Years of practicing and living with Netspeak may lead to the formation of certain writing habits. This would happen when language violations such as spelling mistakes and the misuse of punctuations - which used to be considered as errors in traditional writing - become acceptable, ingrained and fossilized in learners' writing patterns.

Baron, foresees that, "by the time users reached college, they tend not to put a lot of effort into monitoring what they write". By drawing on the concept of "habit strength" offered by John Dewey, Baron believes that after years of frequent and constant practice, learners will naturally employ abbreviations, acronyms and contractions in their traditional writing. She further describes, "Their fingers tend to go on automatic pilot... It is not surprising to see school-appropriate writing habits crop up in Instant Messaging, which is produced on the same keyboard as those formal school assignments” [2].

3.1.2 The need for speed: Failure to Distinguish between Formal and Informal Writing. Next, Ross, as well as many other researchers [17][1][2][12][16][11], suggests the need for speed and the need to be concise as other factors contribute to the emergence of many short forms in Netspeak. "Speedy communication allows less time for careful, organized thought. Partly for this reason, emails, text messages and broadcast messages (instant messages, chat messages) are in many ways stylistically more similar to spoken language than traditional written forms" [17]. As it is easier and faster to write down thoughts in a spoken manner, informality is always seen as an aspect close to online writing practices. Towards certain extent, it may be hard for these learners to distinguish between the formal and informal writing situations, especially when it comes to a formal-online type of writing involving official letters (to be sent via email), online reports, business memos, online bulletin and many more.
3.1.3 Time-Constrained Activities and the Need to be Spontaneous. Some other factors would include the need to produce spontaneous speech, as well as time constraints [2]. In other words, when it comes to time-constrained activities, users tend to ignore the importance of language accuracies and appropriate sentence structures due to the need of instant feedback and speed, especially in discussions that take place in real-time settings [11][21][2]. Those engaged in the real-time online communication were operating at the "lexical-theoretical structural level" that produced significantly shorter sentences since their immediate attention was focused on conveying information directly and spontaneously [21][2]. This habit might be transferred into the formal writing practices, especially when performing timeconstrained tasks such as online assessments, tests or examinations.

3.1.4 A State of Confusion: Respelling Activities Based on Existing Dialects, Informal Spoken Language or Popular Cultures. As the development of Netspeak might be different from one country to another, Ross believes that apart from borrowing some patterns from the English Language, some of the features of Netspeak are actually home grown, and represent its users' identities [17]. Language evolution is an ongoing process, and the development of Netspeak has always been unpredictable, even though it might originate from a rethinking process of some old spelling conventions on media, and not some patterns of language that were derived on their own. Drawing on the same concern, Squires predicts that the development of Netspeak is currently going through the same phases experienced by many other varieties in the process of language establishment that belong to one particular society [20]. Varieties and sub-varieties, including regional dialects, will undergo the process of "enregisterment" whereby, "sets of linguistic features, are conceived as distinctive, imbued with social meaning linked to social personae, and linked to what are perceived as distinct varieties of the language (or registers)".

Categorizing Netspeak as another variety used by a specific group of speakers or users, Squires (2010) believes that Netspeak is a respelling phenomenon; a derivation of earlier communication activities produced by people; highly influenced by users' identity and socio-cultural background. With such familiar L1-related features that are not foreign to its users, confusion will always take place when it comes to the use of Standard English, especially among those who have not mastered the language. 


\section{The study}

By employing both qualitative and quantitative methods, the primary aim of this research would be to examine the fossilization of errors in writing among ESL and EFL learners from two different countries; Malaysia and Jordan. The research focuses on learners' perceptions and feelings towards the use of a proper English Language in both formal and informal writing activities.

\subsection{The Survey}

A set of questionnaire was developed based on several variables forwarded by previous researchers [20][17][1][16][11][21]. These variables helped the participants to relate their daily writing practices (formal and informal) with online communication activities. Items of the survey questions helped the researchers to understand the participants' habitual writing practices. They are also designed to identify whether certain writing habits relate to participants' daily online communication practices; which may lead to the fossilization of errors in their formal writing practice. Apart from that, items of the survey question also uncovered their feelings and perceptions towards the use of a proper English Language in both formal and informal writing activities.

\subsection{Semi Structured Interviews}

As some personal information such as one's attitudes and feelings can never be obtained through mere texts, in-depth interviews with selected participants are highly necessary. This is also important in providing triangulation for the data. Thirty participants took part in the interviews and they were selected from the same groups of participants involved in the first research tool. Findings gathered from the interviews were discussed hand-in-hand with the primary data.

Lists of key themes, issues, and questions were then prepared after analyzing the primary data (the survey). Semi-structured interviews have the advantage as the questions can always be changed, depending on the direction of the interview. An interview guide was prepared, but additional questions were also asked depending on participants’ responses.

\subsection{Research Participants}

The research participants consisted of 300 learners from Malaysia and Jordan. Purposive sampling was employed in selecting these participants. These two different groups of the sample were made up of 150 Malaysians and 150
Jordanians. They represent both ESL (Malaysians) and EFL (Jordanians) learners from two different countries in order to provide a wider coverage of data. Not only that, another aspect that was taken into consideration would be their language choice, as only those who use mostly English when communicating online were considered as participants. This is due to the primary objective of this research, which aims to see the fossilization of errors in writing among both ESL and EFL learners, due to their constant online communication practices.

The participants were born between 1986 and 1993, and they represent the young English Language learners from different parts of both countries. One rationale of selecting participants of this age group would be, they are known as the IT generation who has had the most influence on the Internet and its online language.

\section{Findings and Discussion}

Some early questions pertaining to their regularity of online communication practices were given to these participants. Findings indicate that $72.6 \%$ (109/150 participants) of the Jordanian students communicate online every few hours daily, while 52.6\% (79/150 participants) of the Malaysian students communicate online at least once in every hour, every day. $60 \%$ (90/150 participants) of the Malaysian students check their online messages once in every hour, while $65.3 \%$ (98/150 participants) of the Jordanian students would also do the same. These indicate a highly regular online interaction activity (sending and receiving messages) as a part of their daily routine. The findings supported Tapscott who describes social media as the primary communication platform for the new generation, that replaces the conventional methods of communication such as television, radio and printed media.

As the discussion moves on, to the premise of how online communication habit brings certain impacts on students' formal writing practices, several interesting findings pertaining to this aspect were recorded. Firstly, the finding indicates some contrast

perceptions between both ESL (Malaysians) and EFL (Jordanians) groups of learners. 80\% (120 out of 150 participants) of the ESL learners disagreed that regular online communication activities has affected their ability to use proper English punctuations and spelling. However, more than 70\% of the EFL learners (110 out of 150 participants) agreed to the above statement. Some EFL learners (69 participants/46\%) also agreed that their English Language writing skills has become worse than before, due to regular online communication activities.76\% of the EFL learners (114 out of 150 participants) agreed that online communication activities affect their ability to spell English words correctly while only $36.7 \%$ of the ESL learners 
(55/150 participants) had actually agreed to the same statement. This indicates a contrast perception towards how online communication activities might actually bring impacts on their English languagespelling ability. As EFL learners are more concerned about their language performance and looked at the situation from a negative perspective, the ESL students on the other hand, perceived online communication habit as something that would not jeopardize their English Language-spelling ability.

Another interesting finding would be in terms of students' ability to differentiate between formal and informal types of writing. This is important in signifying learners' writing ability as such confusion or a failure to distinguish between formal and informal writing would bring a tremendous effect on their writing skills and language. After years of online communication practices, $61.3 \%$ of the EFL students (92/150 participants) admitted that they cannot even differentiate between the formal and informal types of writing anymore. As it is always more convenient to express ideas and thoughts in a spoken manner, casualness is always regarded as an element that stays close to online communication activities. It is undeniable that, towards certain extent, these learners might face difficulties in distinguishing between the formal and informal writing activities. The ESL learners, however, are not in favor with such idea as $74 \%$ of (111/150 participants) strongly disagreed that they are unable to differentiate between formal and informal writing.

However, both groups of learners $(52.6 \%$ and $40.6 \%$ ) agreed that online communication activities affect their ability to write effectively, especially in the English Language.It goes hand in hand with findings derived from the interviews as one of the participants agreed that spelling mistakes, which are considered as normal in online communication practices seemed to affect her normal writing behavior. This participant admitted that she has actually begun to transfer some of these online communication habits into her daily writing activities.

A: Facebook...err...I think can influence my writing skills...because I always use short forms on Facebook.

$R$ : You always use short forms on Facebook?

A: Yes...so...err...I put in my writing as well. I also put in my writing.

R: So do you think that Facebook can improve your writing skills?

A: Not really...not really...

\section{**R: Researcher; A: Participant}

The next findings indicate a huge acceptance of informal language, to be employed in both formal and informal writing tasks. Table 1 shows more results of such phenomenon:

Table 1. Informal writing tasks phenomenon

\begin{tabular}{|l|c|c|}
\hline Items: & $\begin{array}{c}\text { ESL } \\
\text { Learners }\end{array}$ & $\begin{array}{c}\text { EFL } \\
\text { learners }\end{array}$ \\
\hline $\begin{array}{l}\text { Always/very } \\
\text { often: }\end{array}$ & Agree & Agree \\
\hline $\begin{array}{l}\text { I use short forms } \\
\text { when I write } \\
\text { formal letters via } \\
\text { e-mail. }\end{array}$ & $\begin{array}{c}\text { 39.3\% (59 } \\
\text { participants) }\end{array}$ & $\begin{array}{c}\text { 28.6\% (43 } \\
\text { participants) }\end{array}$ \\
\hline $\begin{array}{l}\text { I use short forms } \\
\text { in my real writing } \\
\text { activities. }\end{array}$ & $\begin{array}{c}85.3 \% \text { (128 } \\
\text { participants) }\end{array}$ & $\begin{array}{c}24 \% \text { (36 } \\
\text { participants) }\end{array}$ \\
\hline $\begin{array}{l}\text { It is not wrong to } \\
\text { use short forms in } \\
\text { formal writing. }\end{array}$ & $\begin{array}{c}52 \% \text { (78 } \\
\text { participants) }\end{array}$ & $\begin{array}{c}47.3 \%(71 \\
\text { participants) }\end{array}$ \\
\hline $\begin{array}{l}\text { It is not wrong to } \\
\text { use short forms in } \\
\text { writing as long as I } \\
\text { can make people } \\
\text { understand what I } \\
\text { am saying. }\end{array}$ & $\begin{array}{c}87.3 \% \text { (131 } \\
\text { participants) }\end{array}$ & $\begin{array}{c}84.7 \% \text { (127 } \\
\text { participants) }\end{array}$ \\
\hline $\begin{array}{l}\text { It is more } \\
\text { convenient to write } \\
\text { using short forms } \\
\text { in both formal and } \\
\text { informal online } \\
\text { writing activities. }\end{array}$ & participants) & participants) \\
\hline
\end{tabular}

The above findings conform to Fairclough's concept of Informality. Fairclough argues that when there is a "shift in the relationship between spoken and written discourse" the use of spoken language in a written form seems to be accepted by the society. As Faircloug believes that it is all begins with the media, his idea of this transformation from a formal written discourse into a spoken language style of writing is highly reflected in the current situation. The use of short forms in formal letters, for instance, indicates a shift from formal to informal writing practices that seems to become something tolerable among these young ESL and EFL learners. Findings also indicate how the use of informal language in formal writing has actually been accepted as something normal among these learners. As Fairclough foresees that, "the division between speech and writing is no longer the commonsense one it may seem to be, in either direction", it is believed that the patterns of language used online are not exactly a current issue that need to be reprimanded. However, the issue of formality and the suitability of the use of this language in certain formal contexts need to be addressed and taken into consideration. [7] 
The next variable revolves around the idea of "whatever generation" forwarded by Baron, who describes a laid back attitude of taking language accuracy for granted. Findings indicate that $76.7 \%$ (115/150 participants) of the EFL learners [2], while only $33.4 \%$ (50 participants) of the ESL learners admitted that there are times (very often/sometimes) when they use spelling modifications in formal online writing activities as it is perceived as something normal. Not only that, $56 \%$ of the EFL learners (84/150 participants) actually admitted that they always transfer their online communication habits into their real writing activities, while $67.3 \%$ (101/150 participants) of the same group of participants also agreed that they always use the abbreviations that they normally use in their online communication, in their real writing activities.

In one face-to-face interview with a group of participants, it is found that the use of abbreviations is seen as a trend in online communication practices that need to be followed by online users if they do not want to be left behind. The following excerpt taken from one interview session demonstrates the situation:

$R$ : Do you think that by using short forms, the others will be able to understand what you are trying to say?

A: I think everyone will be able to

know...err...because...it's a trend.

$R:$ It's a trend...okay...

A: For example, L 8 T R...later.

$R: L 8 T R$ ?

A: Eh...L T 8 R...later.

$R:$ L...T...number 8...R? Later?

A: Yes...later.

\section{***R: Researcher, A: Participant}

As demonstrated in the above excerpt, one of the participants, known as A, believed that this particular feature is normally intelligible with everyone, thus it is not a problem for her to use it in writing, regardless of its purpose and function. These findings support Baron's [2] idea that suggests how constant online communication practices may actually develop a laid-back attitude towards language accuracy in writing. As people are beginning to feel more and more comfortable with this new pattern of language, Baron perceives the current situation as the beginning of a new set of language rules, cultures and norms of interactions. She further states that, "there is an international perception that computers and mobile phones are affecting everyday language, and these effects are generally not for the better" [2]. As people are becoming less and less serious about the importance of linguistic consistency, Baron also speculates that:

\begin{abstract}
We are raising a generation of language users (who, in turn, influenced the linguistic patterns of their elders) that genuinely does not care about a whole range of language rules. Whether the issue is spelling or punctuation, verb agreement or pronoun choice, there seems to be a growing sense of laissez-faire when it comes to linguistic consistency[2].
\end{abstract}

The findings also indicate some reasons behind the problems with spelling among the research participants. As $79.3 \%$ of the ESL learners (119/150 participants) as well as $93.3 \%$ of the EFL learners (140/150 participants) admitted that they always spell English words according to their pronunciation. This pronunciation, however, is heavily influenced by their first languages, dialects or the simplification of pronunciation; one of the prominent features of the English Language low varieties that provides a sense of belonging, normally employed by second/foreign language speakers in their daily interaction activity. As these learners also admitted that they normally use short forms when they do not know how to spell certain words in both online communication activities as well as real writing, the fossilization of errors among these participants therefore, could rather be seen as a natural outcome of one's language learning process. The findings supported Selinker's theory of Interlanguage that explains learners' failure of separating between certain features of their first language and the features of the English Language, resulting to the high interference and influence of L1 and Netspeak features in their use of English.

\section{Conclusion}

Even though the advent of online language in most developing countries stands at its novelty stage, the mark of this language however, is already noticeable. Since English language performs as a second or a foreign language in many non-speaking English countries, it is concerned that online language might interfere with this entire process of English language acquisition and learning or even hinders the entire learning process. With the lack of natural learning environment and huge exposure to online language, younger language learners (especially foreign language learners) may assume this as something confusing or perhaps acceptable. It is crucially important to make these students aware that online language is not yet acceptable in a traditional or formal writing convention; therefore 
preventive measures and precautionary actions should be taken in no time.

\section{Input 3: Constant Use of Netspeak}

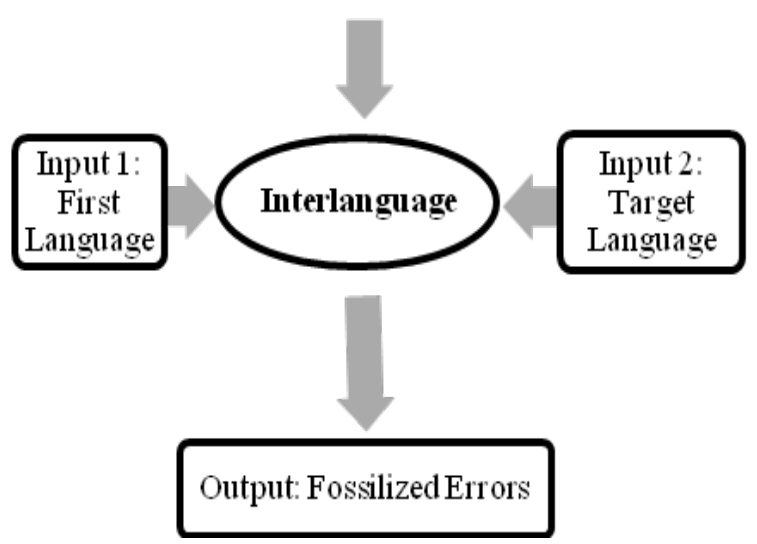

Figure 2: Netspeak as an extra input to the Interlanguage phenomenon

With some relevant underpinning theories of second language acquisition such as Interlanguage, future research can also look at the effects of this language on students' writing habits and practices. As far as Baron [2] and many other scholars are concerned [13][8][5][4], the fossilization of errors in online communication writing practices may result in certain outcomes and negative consequences. Without a doubt, this fossilization of errors, regardless of its nature; (be it spelling errors or spelling modifications, omission of verbs and articles and many other forms of grammatical errors that are listed as the unique patterns of Netspeak) may lead to certain influences on learners' language development, especially young language learners [2]. As demonstrated in the above figure, a constant use of Netspeak features might hinder the process of second or foreign language learning as it creates confusions by giving an extra input to the existing Interlanguage phenomenon experienced by most ESL/EFL learners. However, in-depth research studies are greatly needed using a more comprehensive method such as analyzing students' written products using content analysis, as the findings of these studies can be extremely beneficial for educators to think of some possible solutions in dealing with the issue.

With a new word such as 'unfriend' (which was derived from social networking sites like Facebook and Friendster) being included in The New Oxford Dictionary as 'Word of 2009', it is predicted that the current situation is not going to last that long. More changes and modifications will come in, as more modern verbs that were regarded as errors not long ago are adapted and considered acceptable in this new genre of modern writing convention. The English world is becoming more lenient in tolerating this invention of modern words. As Thurlow proclaims, "no lay speakers nowadays actually use the English of Shakespeare" Thurlow, it is also a concern that with the drastic changes shown by youngsters in their patterns of online writing practices, along with all these spelling modifications will slowly become acceptable as a part of the modern writing convention regardless of their purpose and function [25]. This is not surprising, and in fact, the early signs of the informalization phenomenon in formal writing convention have already started to appear, especially among the nonnative English speakers[4]. However, future research is greatly needed in addressing this issue by identifying the contributing factors, and offering some possible solutions to the problem.

Human languages grow hand in hand with the development of technology and there's nothing much that we can do about it. However, preventive measures can always be taken in handling this issue from becoming worse. As formality is still a very prominent aspect in most writing conventions, specific language control devices or standard rules and regulations need to be re-established and imposed, before it is too late to do so.

\section{References}

[1] Baron, S. N. (2005) Instant Messaging by American College Students: A Case Study in Computer-Mediated Communication. Paper Presented in "Language on the Internet: American Association for the Advancement of Science and Annual Meeting, February 17-21, 2005”.

[2] Baron, S. N. (2008) Always On: Language in an Online and Mobile World. Oxford University Press, New York.

[3] Baron, S. N. (2009) The Myth of Impoverished Signal: Dispelling the Spoken-Language Fallacy for Emoticons in Online Communication. Retrieved at http://www1.american.edu/tesol/Baron-

AAASIM\%20by\%American\%20College\%20Students.pdf

[4] Berman, I. (2006) Email-“Inspired” Changes in Nonnative Legal Discourse. Digital Peer Publishing. urn: nbn: de: 0009-7-3726. Retrieved: 10.1.2010 at http://www.languageatinternet.de/articles/2006/372

[5] Crystal, D. (2006) Language and the Internet. Second Edition. Cambridge, UK: Cambridge University Press.

[6] Choi, H. (2003) Literacy practices in the digital age. Dong-A Newspaper. Retrieved February $24^{\text {th }}, 2005$ at: http://www.donga.com/docs/magazine/shin/2003/11/07/20 0311070500002/200311070500002_1.html

[7] Fairclough, N. (1992) Discourse and Social Change. Polity Press, Oxford. 
[8] Greenfield, M. P. and Subrahmanyam, K. (2003) Online Discourse in Teen Chatroom: New Codes and New Modes of Coherence in Visual Medium. Applied Developmental Psychology. 24 (2003) 713-738. Elsvier Inc. 2003.

[9] Johnova, M. (2004) The Language of Chat. An Online Journal of Modern Philology. ISSN 1214-5505. Retrieved: 28.12.2009

http://philologica.net/studia/20040113000003.htm

[10] Kern, R.G. (1995) Restructuring classroom interaction with networked computers: effects on quantity and characteristics of language production. Modern Language Journal 79, 457-476.

[11] Lee, J. S. (2006) Exploring the Relationship between Electronic Literacy and Heritage Language Maintenance. Language Learning and Technology. May 2006. Vol.10.No.2.pp93-113. Retrieved : 21.3.2009 at http://llt.msu.edu/vol10num2/lee

[12] Maynor, N. (1994) The language of electronic mail: written speech? In G. D. Little \& M. Montgomery, eds., Centennial Usage Studies, pp. 48-54. Tuscaloosa: Alabama UP.

[13] Montero-Fleta, B, Montesinos-Lopez, A, SabaterPerez,C and Turney,E. (2008). Computer Mediated Communication and Informalization of Discourse: The Influence of Culture and Subject Matter. Journal of Pragmatics. ScienceDirect.2008 Elsevier B.V. 41 (2009) 770-779. Retrieved: 28.12.2009 at www.sciencedirect.com

[14] Montero-Fleta, B, Watts, F, Carbonell-Garcia, A. (2007) Discussion Forum Interactions: Text and Context. Journal of System. ScienceDirect. 2007 Elsevier Ltd. 35 (2007) 566-582. Retrieved: 28.12.2009 at www.sciencedirect.com

[15] O’ Grady, W. and Archibald, J. (2008) Contemporary Lingusitic Analysis: An Introduction ( $6^{\text {th }}$ Edition). Toronto: Pearson Longman.

[16] Randall, N. (2002) Lingo Online: A Report on the Language of the Keyboard Generation. Retrieved May 11, 2011 from http://www.arts.uwaterloo.ca/ nrandall/lingoonline.htm

[17] Ross, N. (2006) Writing in the Information Age. English Today 87, Vol. 22, No.3 (July 2006). Cambridge: Cambridge University Press

[18] Stephen D. K. (1981) Second Language Acquisition and Second Language Learning. Pergamon Press Inc.

[19] Smith, B. (2003) Computer-Mediated Negotiated Interaction: An Expanded Model. The Modern Language Journal, 87(1), 38-57.

[20] Squires, L. (2010) Enregistering Internet Language. Language in Society 39, 457-492. Cambridge: Cambridge University Press.
[21] Satillo, M. S. (2000) Discourse Functions and Syntactic Complexity in Synchronous and Asynchronous Communication. Retrieved at: http://ltt.msu.edu/ vol4num1/satillo/default.html

[22] Shortis, T. (2007) Gr8 Txtpectations: The Creativity of Text Spelling. Retrieved: 28.12.2009 at http://www.nte.org.uk/.../00014-edmjune_07shortismakepublic.pdf

[23] Shortis, T. (2007) The Texture of Internet: Netlinguistics in Progress. Cambridge Scholars Publishing. Available online at: http://www.c-sp.org/Flyers/9781847181732-sample.pdf

[24] Tagliamonte, Sali A., \& Denis, Derek. (2008) Linguistic Ruin? LOL! Instant Messaging and Teen Language. American Speech 83:3-34.

[25] Thurlow, C. (2006) From Statistical Panic to Moral Panic: The Metadiscursive Construction and Popular Exaggeration of New Media Language in the Print Media. Journal of Computer Mediated Communication. (2006) 667-701. $\quad$ Retrieved 28.12.2009 at http://faculty.washington.edu/thurlow/papers/Thurlow(200 6)-jcmc.pdf 